\title{
Acoustic in-ice positioning in the Enceladus Explorer project
}

\author{
Dmitry ELISEEV, ${ }^{1}$ Dirk HEINEN, ${ }^{1}$ Klaus HELBING, ${ }^{2}$ Ruth HOFFMANN, ${ }^{2}$ \\ Uwe NAUMANN, ${ }^{2}$ Franziska SCHOLZ, ${ }^{1}$ Christopher WIEBUSCH, ${ }^{1}$ Simon ZIERKE $^{1}$ \\ ${ }^{1}$ III. Physikalisches Institut, RWTH Aachen University, Aachen, Germany \\ E-mail: heinen@physik.rwth-aachen.de \\ ${ }^{2}$ Department of Physics, University of Wuppertal, Wuppertal, Germany
}

\begin{abstract}
The Enceladus Explorer project is a preparatory study for a future space mission to Saturn's moon, Enceladus. Its ultimate goal is to probe liquid-water pockets below the ice surface of Enceladus for signatures of life. A probe could be based on the IceMole concept, which melts curved trajectories through the ice. In the Enceladus Explorer project, a specialized IceMole probe for a terrestrial test scenario is in development. The goal of this exploratory study is to probe water from a liquid crevasse close to Blood Falls at Taylor Glacier, Antarctica. To navigate such a probe it is essential to be able to determine its position and monitor its trajectory. Part of the navigation system is the in-ice acoustic positioning system. For this, the head of the IceMole is equipped with acoustic sensors, which receive signals from synchronized acoustic emitters situated at the ice surface. Based on the measured propagation times, the speed of sound in ice and the positions of the emitters at the surface, the position of the IceMole can be determined by trilateration techniques. Here we present the developed acoustic positioning system, which is designed to track the in-ice melting probe up to distances of $100 \mathrm{~m}$ in glacier ice. Results from full-system tests in water and a first field test on Morteratschgletscher, Switzerland, are discussed.
\end{abstract}

KEYWORDS: glaciological instruments and methods, ice physics, subglacial lakes

\section{INTRODUCTION}

A promising candidate in the search for extraterrestrial life is Enceladus, a moon of Saturn, which is completely covered by an ice crust (Brown and others, 2006). The Cassini spacecraft identified a geologically young region at the south pole of Enceladus (Porco and others, 2006). The temperatures measured in this region are too high to be explained by solar heating, which indicates an internal energy source within Enceladus. Furthermore, Cassini found four sub-parallel, linear depressions in the south polar region of Enceladus, which are called 'tiger stripes'. In this geologically active area, cryovolcanoes eject geyserlike jets of water vapour, ice, salt and organic molecules into space (Fig. 1). The composition of these plumes was measured by Cassini in 2005 (Waite and others, 2006). Recently, the Cassini spacecraft provided strong evidence for a large underground ocean of liquid water $\sim 40 \mathrm{~km}$ below Enceladus' south pole (less and others, 2014). These observations strengthen the possibility of the existence of extraterrestrial life on Enceladus. For further investigation it is essential to probe the liquid water. It is less technically challenging to tap the vents of one of the geysers than to probe the underground ocean directly. To perform this task, a spacecraft would land near to one of the geysers and an in-ice probe would approach the vent to collect a liquid sample. First, the in-ice rover has to be manoeuvrable through the ice to navigate to the vent. Second, the rover needs an in-ice positioning system, as well as a reconnaissance system, to identify the vent and obstacles within the ice. In addition, a clean access strategy, a contamination-free method for the sampling and in situ analysis are needed. Furthermore, the mission has to be accomplished autonomously.

\section{ENCELADUS EXPLORER PROJECT}

The Enceladus Explorer (EnEx) project is a first step in the development of technology for an Enceladus mission. As a matter of principle, technology for space missions is tested in terrestrial test scenarios prior to use in space. The terrestrial test scenario for the EnEx project is the 'Blood Falls' mission. In cooperation with the Minimally Invasive Direct Glacial Exploration (MIDGE) project, this mission is scheduled for November 2014 (Dachwald and others, 2014). About $400 \mathrm{~m}$ beneath Taylor Glacier, Antarctica, lies a subglacial lake, which has been isolated for at least 1.5 Ma (Mikucki and others, 2009). Some brine from this subglacial lake emerges sporadically at the glacier tongue. This iron-rich outflow colours the glacier tongue red, hence the name 'Blood Falls'. The goal for EnEx and MIDGE is to extract a clean sample from the brine-filled fissure within the glacier next to Blood Falls.

\section{IceMole probe}

A specialized probe, called the 'IceMole', has been developed as a carrier system for all subsystems to accomplish the Blood Falls mission. The IceMole is a manoeuvrable in-ice probe, which combines a melting head with an ice screw for forward thrust and movement even against gravity (Dachwald and others, 2014). Partial heating of the IceMole melting head allows navigation of curved trajectories through the ice.

Attached to the melting head is a square pipe with dimensions of $15 \mathrm{~cm} \times 15 \mathrm{~cm} \times 180 \mathrm{~cm}$ and sealed by a back plate. The $2.9 \mathrm{~kW}$ power for forward melting leads to a maximal velocity of the IceMole of $\sim 1.1 \mathrm{~m} \mathrm{~h}^{-1}$. Due to the length of the probe and additional side melters, a minimal curve radius of $\sim 10 \mathrm{~m}$ can be achieved. The meltwater is 


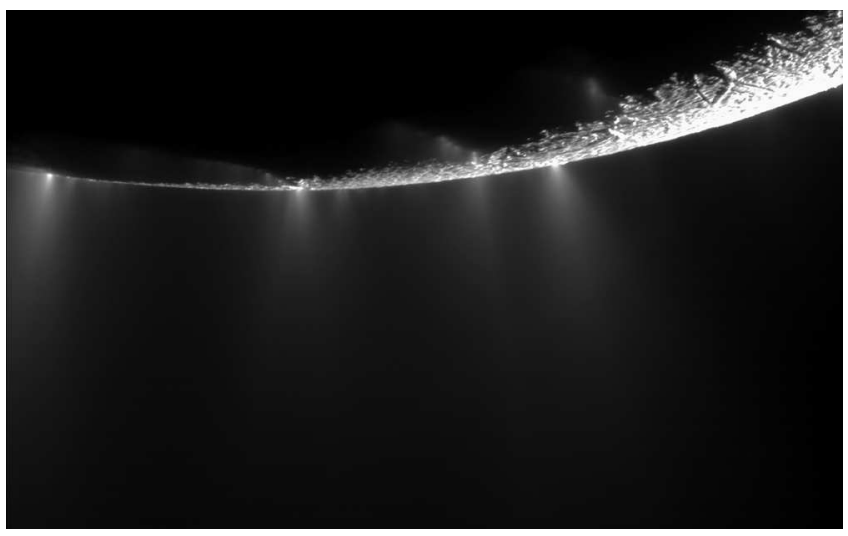

Fig. 1. Photograph of the plumes in the south polar region of Enceladus. Image credit: NASA/Jet Propulsion Laboratory (JPL)/SSI.

pumped out of the melting channel to allow the IceMole to be recovered. The probe is retrieved backwards with a steel cable once the trajectory has been completed and a sample taken. The current design allows trajectories with a maximum length of $\sim 80 \mathrm{~m}$. To retrieve a clean sample from the subglacial brine, the clean access strategy is a multi-step programme (Dachwald and others, 2014). Just prior to taking the sample, an in situ decontamination procedure is performed. Then the IceMole taps the fissure with a pneumatic needle. In total, $1 \mathrm{~L}$ of brine is pumped through the needle into sampling bags located within the IceMole payload bay.

\section{Navigation system}

The manoeuvrability of the melting probe requires knowledge about its position and heading. To avoid obstacles and to find the point of interest, the forefield of the probe needs to be scanned. The IceMole has dedicated subsystems to provide this information. One subsystem is responsible for the inertial navigation and guidance (Niedermeier and others, 2014). It uses an inertial measurement unit, which is equipped with accelerometers and gyroscopes. The heading information is provided by a differential magnetometer system with one flux-gate magnetometer integrated into the probe, and a second reference magnetometer on the surface. An axial feed sensor is connected to the screw as an odometer and provides measurement of the distance covered. To provide information on the forefield, the probe is equipped with an acoustic reconnaissance system. This subsystem uses ultrasonic phased arrays integrated in the IceMole head for sonographic imaging. The absolute position is provided by the acoustic positioning system (APS) described in this paper. All sensor information is collected, combined and visualized at the surface.

\section{ACOUSTIC POSITIONING SYSTEM}

In-ice positioning is challenging, due to the extreme conditions within cold glaciers and because conventional optical and GPS-based positioning methods fail. Small sensors are required to allow integration into a melting probe. A first approach would be to use a radar-like system. The problem with using low-frequency radio signals is that adequate antennas would be rather large. Furthermore, difficulties arise due to different types of polarization. A promising approach is to use a sonar-like system with

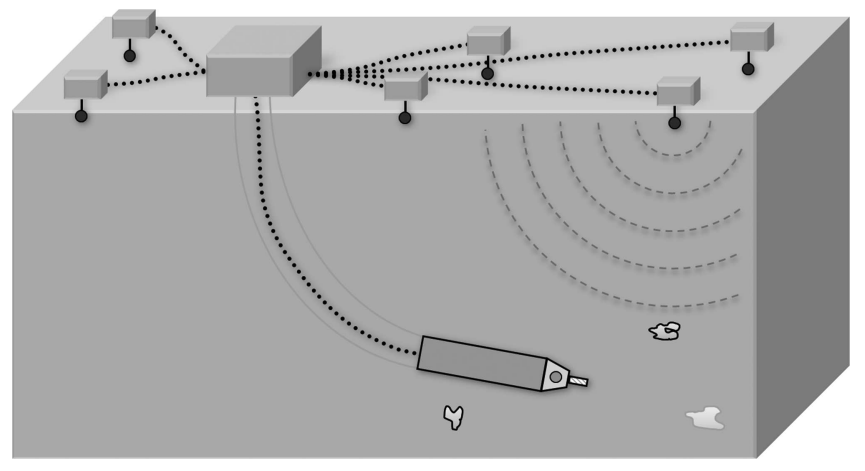

Fig. 2. Principle of the APS. The absolute position of the IceMole is determined by trilateration of ultrasonic pulses from several emitters.

frequencies of $\sim 20 \mathrm{kHz}$, optimized for in-ice use. Such a system allows the design of small sensors. The measured acoustic absorption length of $\sim 300 \mathrm{~m}$ (IceCube Collaboration, 2011) in solid glacier ice could permit a large operating range. Such an APS has been developed in the Enceladus Explorer project. This system is designed to track the IceMole within a $100 \mathrm{~m}$ trajectory through ice with an accuracy $<1 \mathrm{~m}$.

\section{Principle and overview}

The APS provides the absolute position of the probe based on the idea of trilateration (Fig. 2). Trilateration is a method to determine the position of an object by measuring the distances to at least three other objects at known positions. In this project the unknown position is the location of the IceMole, while the positions of the emitters at the surface are known. The distances are determined by measuring the propagation time of the signals from the transducers to the receivers located in the IceMole head. The transducers require high-voltage pulses to achieve a reasonable power output. To avoid high voltages and electromagnetic noise within the probe itself, the transducers are installed at the glacier surface, while the receivers are integrated into the probe's head. This does not limit the size of the transducers, which need to be $\sim 10 \mathrm{~cm}$ for a resonance in this low-frequency ultrasonic range. To calculate the distance, a precise estimation of the speed of sound in ice is needed. Its value can be determined by measuring the time a signal needs to travel a known distance. This can be done by taking measurements from one transducer to another. Three signal paths are the minimum required for the trilateration. By over-constraining the measurement with more signal paths, the precision of the positioning can be enhanced and the speed of sound can be determined as an additional parameter.

\section{Emitter and surface components}

The transducers (ITC-1001, International Transducer Cooperation) are spherical sonar pulse emitters with a diameter of $\sim 10 \mathrm{~cm}$ and a resonance frequency of $\sim 18 \mathrm{kHz}$. They are placed $\sim 0.5 \mathrm{~m}$ below the ice surface for optimal coupling and to reduce the effects of inclusions, smaller cracks and inhomogeneities in the upper layers of the ice. The holes, in which the transducers are placed, are filled with water for good coupling to the glacier ice. Depending on the glacier temperature the holes either stay water-filled or refreeze. 


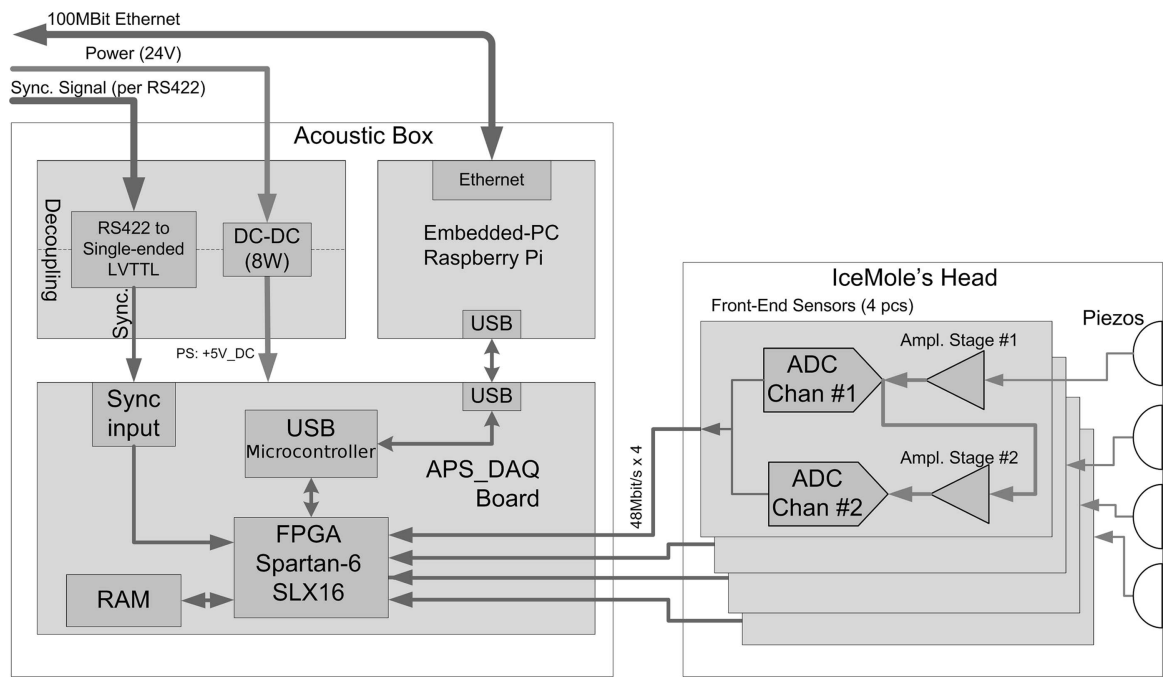

Fig. 3. Scheme of the APS data-acquisition microcontroller.

The transducer system consists of six stations which are connected and controlled through a field-programmable gate array (FPGA)-based central transducer unit (CTU). The CTU distributes a differential pulse per second (PPS) signal by an electrical connection to the IceMole to synchronize with the other subsystems with an accuracy $<1 \mu \mathrm{s}$. To distribute the global time, a GPS antenna can be connected to the CTU, otherwise a local reference time is sent. For communication the CTU is connected via $100 \mathrm{Mbits}^{-1}$ Ethernet to the local area network of the IceMole. Each station contains one front-end transducer unit (FTU) and one acoustic transducer. The FTU amplifies the signal coming from the CTU and transfers it to the transducer. In addition to signal emission for the APS, the transducers can also be used as receivers. This allows measurements from one transducer to another to be performed in order to investigate the ice properties, especially the speed of sound. Received signals are amplified by the FTU and transferred back to the CTU, where the signals are distributed to a National Instruments USB-6366 data-acquisition module. This module records the signals and is controlled by an operators' notebook computer. To calculate the position of the probe via trilateration, it is essential to know the position of all transducers accurately. This measurement is performed with a differential GPS receiver and a GPS reference station with a typical accuracy of a few centimetres.

\section{Receiver and front-end electronics}

Four acoustic sensors in the IceMole head receive the signals from the transducers at the ice surface. Each acoustic sensor is based on a piezoelectric ceramic disc (PIC-255, Physik Instrumente $\mathrm{GmbH} \& \mathrm{Co}$. KG), which is encased in a metal housing. The material of the disc is lead zirconate titanate (PZT), the disc diameter is $16 \mathrm{~mm}$ and its thickness is $3 \mathrm{~mm}$. The housing protects the sensor mechanically and reduces pick-up of electromagnetic noise. The disc is pressed against the inner side of the IceMole head to achieve good acoustic coupling. This also couples one electrical contact of the PZT disc to the electrical potential of the IceMole chassis. The other electrical contact is directly coupled to the front-end electronics. The zero potential of the front-end circuit is also coupled to the IceMole chassis to avoid electrical noise pick-up. Two stages, one with low $(+53 \mathrm{~dB})$ gain and one with high $(+80 \mathrm{~dB})$ gain, amplify the signals in a frequency range 10 $300 \mathrm{kHz}$. Both stages are digitized via analogue/digital converters with a $2 \mathrm{MS} \mathrm{s}^{-1}$ sampling rate and $12 \mathrm{bit}$ resolution. The digital, differential signals are transferred into the 'acoustic box' inside the IceMole payload bay for further handling.

\section{Data-acquisition system}

Data acquisition and preprocessing is via the 'acoustic dataacquisition board' and the 'acoustic embedded PC'. These are located inside the acoustic box situated in the payload bay of the IceMole. The FPGA-based acoustic data-acquisition board simultaneously receives the digital signals from all sensors, stores the waveforms and then transfers these via USB 2.0 to the embedded PC. The use of a low-cost, commercially available embedded PC (Raspberry Pi Model B Rev. 2, Raspberry Pi Foundation) is sufficient. The synchronization between the CTU and the acoustic data-acquisition system in the IceMole is via a dedicated electrical signal cable. The CTU sends 1 PPS as a differential signal which is decoupled in the acoustic box. The acoustic data-acquisition board receives this signal and uses it to synchronize the data acquisition. All other communication between the different systems is performed digitally via Ethernet. The dataacquisition system is powered by the $24 \mathrm{~V}$ IceMole subsystem power supply. In the acoustic box the power supply connections are galvanically isolated from the IceMole on a separated power converter board.

\section{Measuring protocol and data handling}

The operator initiates a measurement cycle via a network command from the surface PC to the acoustic box embedded PC. At the same time the IceMole is halted by shutting down the heaters. By keeping the torque on the ice screw, the IceMole head is pulled against the ice to achieve good acoustic coupling. Then the embedded PC sends another network command to the CTU to start the signal generation. From the start time of the transducer cycle, the embedded PC calculates the start times for the individual data-acquisition windows with respect to the last synchronization signal. By default the sampling window is $32 \mathrm{~ms}$ long and starts $1 \mathrm{~ms}$ before the signal generation. Several 


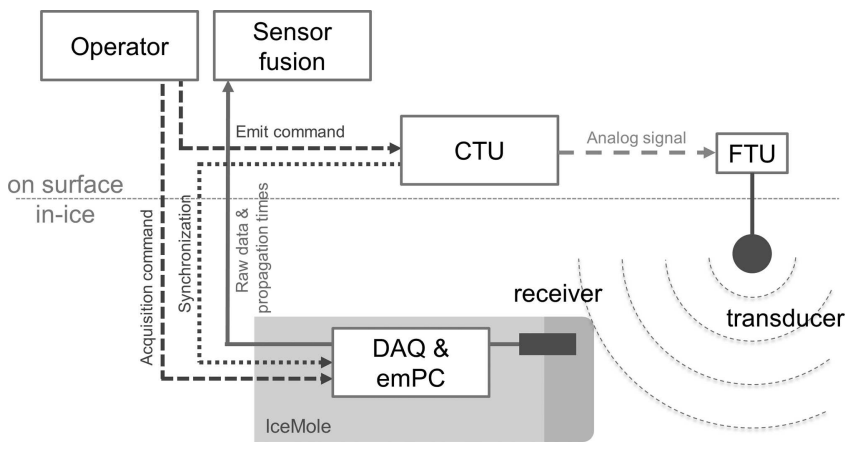

Fig. 4. Flow chart of the APS, showing all essential parts of the system. CTU: central transducer unit; FTU: front-end transducer unit; emPC: embedded PC; DAQ: data-acquisition system.

pulses are emitted, separated by $50 \mathrm{~ms}$. In each measurement cycle, 32 pulses are recorded for each transducer as digitized waveforms. After this the data preprocessing is performed. For each sensor all recorded waveforms are averaged and filtered with a Fourier filter to reduce noise, using a passband of $17.3-26.7 \mathrm{kHz}$. The corresponding window function is defined as 1 for the range $18-26 \mathrm{kHz}$ with Gaussian tails with a $1 \mathrm{kHz}$ standard deviation. From these filtered waveforms the signal arrival times are determined by searching for the first time the noise level is surpassed by a factor of five. The noise level is defined as the standard deviation of the first millisecond of data, which is recorded before the signal generation started. The raw data waveforms and the signal arrival times are transmitted to the central database at the surface. With the determined signal arrival times, speed of sound and known transducer positions the absolute position of the probe is calculated via trilateration.

Figure 4 shows a flow diagram for the entire APS.

\section{FIELD TESTS}

A proof of principle and several development stages of the systems were tested during test campaigns in the field. During summer of each year of the project (2012, 2013, 2014) a field test was carried out on Morteratschgletscher, Switzerland. Furthermore, in autumn 2013 the full system was tested at Canada Glacier, Antarctica. Finally, the Blood Falls mission is planned for November 2014 at Taylor Glacier. The principle of the acoustic positioning was initially tested in summer 2012 in a test campaign. The first full-system test in ice was successfully carried out in summer 2013. The acoustic reconnaissance system took part in this test as a laboratory system. For the test in autumn 2013 the main goals were to test the IceMole in cold glacier ice and the clean access strategy; both were demonstrated successfully. The summer 2014 field test was to finalize the system for the Blood Falls mission, with primary goals of testing the final hardware and software configuration in the field, recording navigation data and training the operators for the final Blood Falls mission.

\section{Proof-of-principle campaign}

The principle of acoustic positioning in glacier ice was tested first on Morteratschgletscher in summer 2012. Several holes were melted vertically into the glacier, and they remained water-filled. One ITC-1001 transducer for signal generation and an array of four analogue ultrasonic sensors were inserted into the holes. Several sine bursts, each with five cycles and frequencies of 30, 45 and $60 \mathrm{kHz}$, were generated. The signals were acquired by a National Instrument USB-6366 data-acquisition module. Several measurements were taken with propagation distances up to $30 \mathrm{~m}$ and a depth of several metres. Signals up to $30 \mathrm{~m}$ were recorded as shown in Figure 5.

\section{System tests in water}

Testing the EnEx acoustic navigation concept in the laboratory is a challenge. The production of sufficiently large amounts of ice is time-consuming and expensive. Furthermore, changing the position of the tested equipment is impossible. The substitution of ice with liquid water allows swimming pools to be used, where the equipment can be easily accessible and movable. Since our system works only with P-waves, the main difference is the speed of sound, which is $\sim 1500 \mathrm{~m} \mathrm{~s}^{-1}$ in water and $\sim 3900 \mathrm{~m} \mathrm{~s}^{-1}$ in ice (IceCube Collaboration, 2011). Besides this difference the acoustic properties of ice and water are sufficiently comparable for system tests.

A local public swimming pool was used, with dimensions $14 \mathrm{~m} \times 17.5 \mathrm{~m}$ and a depth of $4.5 \mathrm{~m}$. Here several development stages from the first APS prototype sensor with a laboratory data-acquisition system to the fully integrated IceMole were tested. Figure 6 shows the scheme of the installation for the full-system test in water. The IceMole and the transducers were mounted $2 \mathrm{~m}$ below mobile rafts. The rafts were fixed by tethering ropes to the sides of the pool. White cardboard cylinders were mounted on top of the rafts as targets for measuring the distance to reference points with a laser odometer. The position of the rafts on the water was determined from the distance to the reference points.

In a first full-system test, the angular sensitivity of the IceMole was measured. The IceMole was located in the centre of the pool and one transducer was moved in several steps around the IceMole with distances of $\sim 4-8 \mathrm{~m}$. At every step a signal from the transducer was emitted and recorded with the sensors in the IceMole head. The $1 / r$-distance dependence of the measured amplitude was corrected by multiplying by the distance. The differences between measured amplitude and maximum amplitude are plotted against the angle in Figure 7 . The maximal sensitivity is found in the direction of the screw, the minimal sensitivity in the direction of the back plate. To the sides the received amplitude differs from maximal amplitude by $<5 \mathrm{~dB}$ up to $\pm 140^{\circ}$ polar angle.

In another test scenario the IceMole was positioned at different locations along a trajectory inside the pool. This test showed the functionality of the positioning system and gave an estimate of the expected uncertainties. For this test a full measurement cycle with four installed emitters was performed at every location. Afterwards the position of the IceMole was reconstructed.

Figure 8 shows the reconstruction of five positions of the raft and the reconstructed IceMole positions along the trajectory inside the pool. The difference between the reconstruction and the expected position is $<0.5 \mathrm{~m}$. The constant offset between the reconstruction and the expected position may arise from a systematic shift between the IceMole head and the reference targets on the rafts. The reconstructed points are in agreement with the actual 

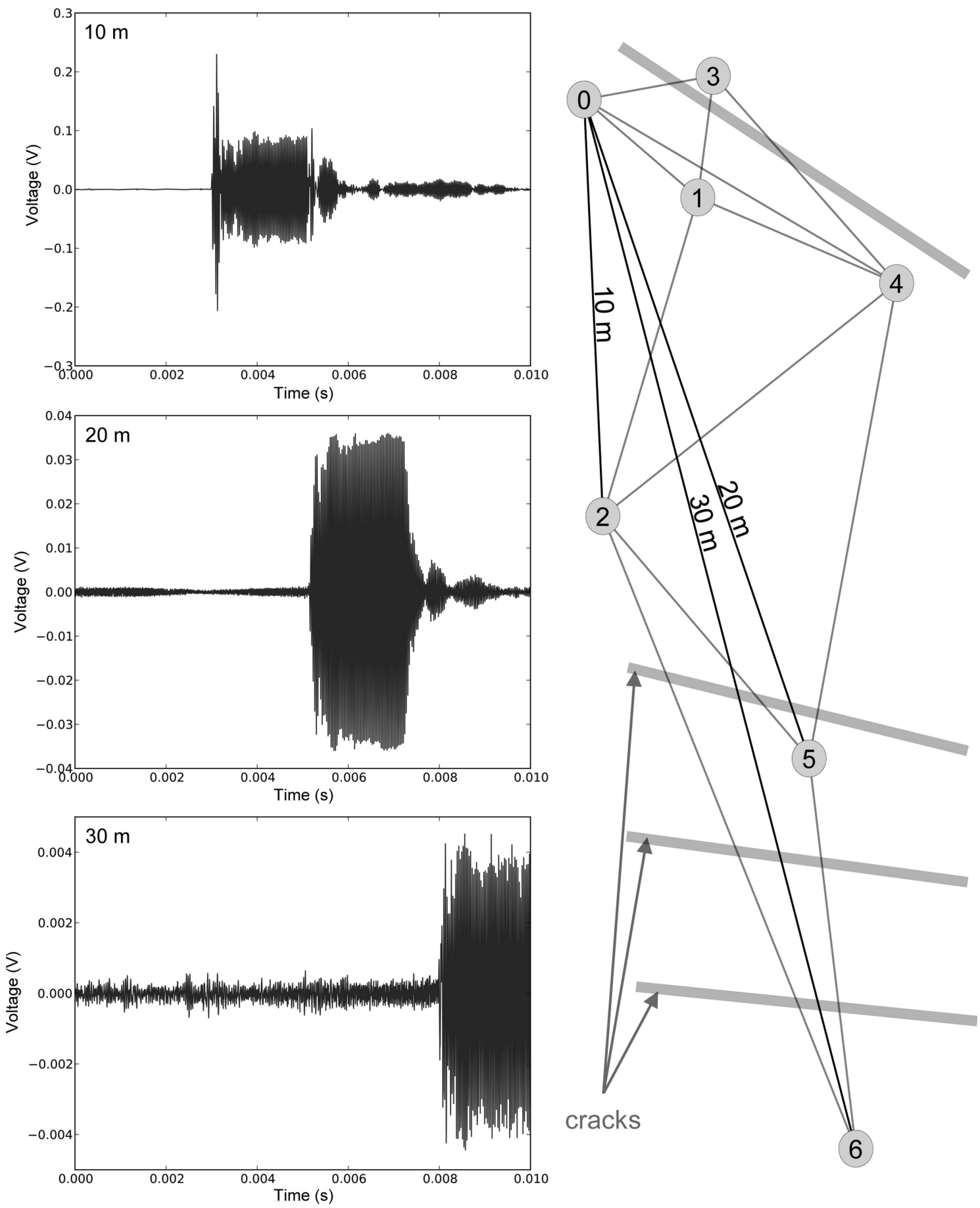

6

Fig. 5. Waveforms of different measurements, and schema of the test site of the APS proof of principle. The schema shows the top view of the melted holes with the corresponding distances between the holes. The waveforms were recorded while the receivers were in hole 0 and the transducer in hole 2,5 or 6 . Note the different scales on the $y$-axis.

position within the measured uncertainties and are below the required accuracy of $1.0 \mathrm{~m}$. This test showed that the APS was fully functional and ready to be tested in glacier ice.

\section{First in situ results in glacier ice}

The fully integrated APS was successfully tested on Morteratschgletscher in summer 2013 and on Canada Glacier in autumn 2013. The trajectories were driven in the upper layers of the ice within depths of $\sim 5 \mathrm{~m}$. The speed of sound in the ice $\left(\sim 3600 \mathrm{~m} \mathrm{~s}^{-1}\right)$ was determined by transducer-to-transducer measurements. An example of one of the transducer signals received at the IceMole can be seen in Figure 9. The pulse can easily be identified. The reconstructed trajectory of the rover is shown as crosses in Figure 10. Only the signals from transducers with a sufficient signal-to-noise ratio were used for the trajectory reconstruction. For this reason most of the reconstructed positions are based on signals from only three transducers. Due to this and the inhomogeneities in the speed of sound, the errors of the positioning in the Morteratsch field test were $0.3-2 \mathrm{~m}$. The errors represent the uncertainties of the trilateration algorithm. Signals from distances up to $20 \mathrm{~m}$ were registered. The first test in Antarctica, in autumn 2013, was also successful. Small cracks, which would be water-filled in a 


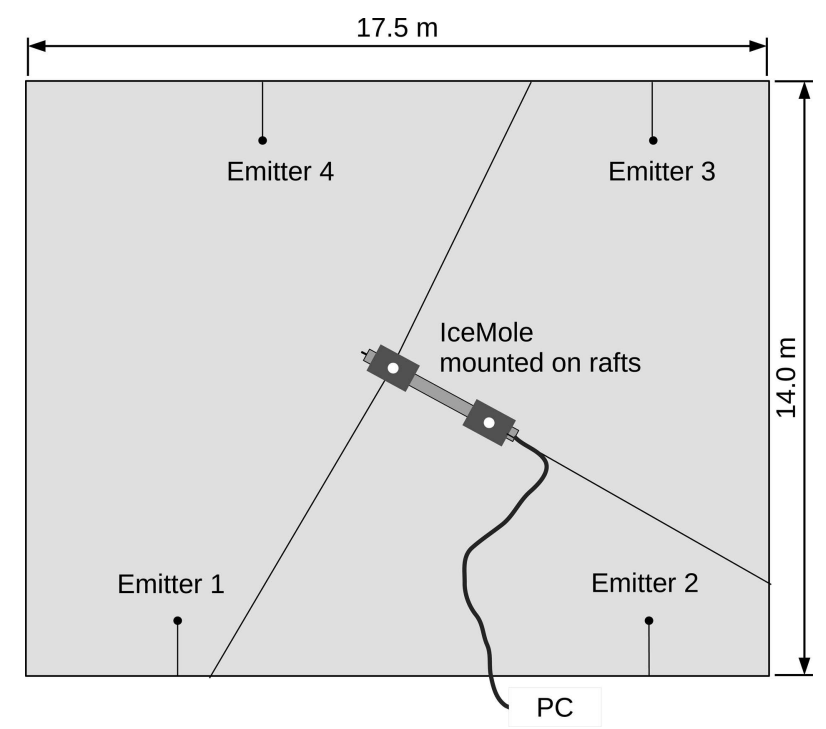

Fig. 6. Sketch of the set-up for the full-system tests in water. IceMole is scaled by a factor of 2 .

temperate glacier, were identified as a possible critical issue for acoustic signal propagation in a dry glacier. This test showed that acoustic signals are not substantially degraded by this effect and that the quality is primarily determined by the coupling of the acoustic transducers to the ice.

To detect very weak signals, and therefore achieve a larger detection range, the frequency filters were optimized. A design study verifies that an infinite impulse response filter (Meyer, 2011) with a passband of $17-25 \mathrm{kHz}$ and a Chebyshev type 1 filter design (Meyer, 2011) gave the best results. An increase in the signal-to-noise ratio of about a factor of two was accomplished. Improved front-end electronics with an optimized two-stage analogue filter were developed for the summer 2014 field test. Further analysis shows that the accuracy of the positioning can be further increased by using more transducer signals, a higher

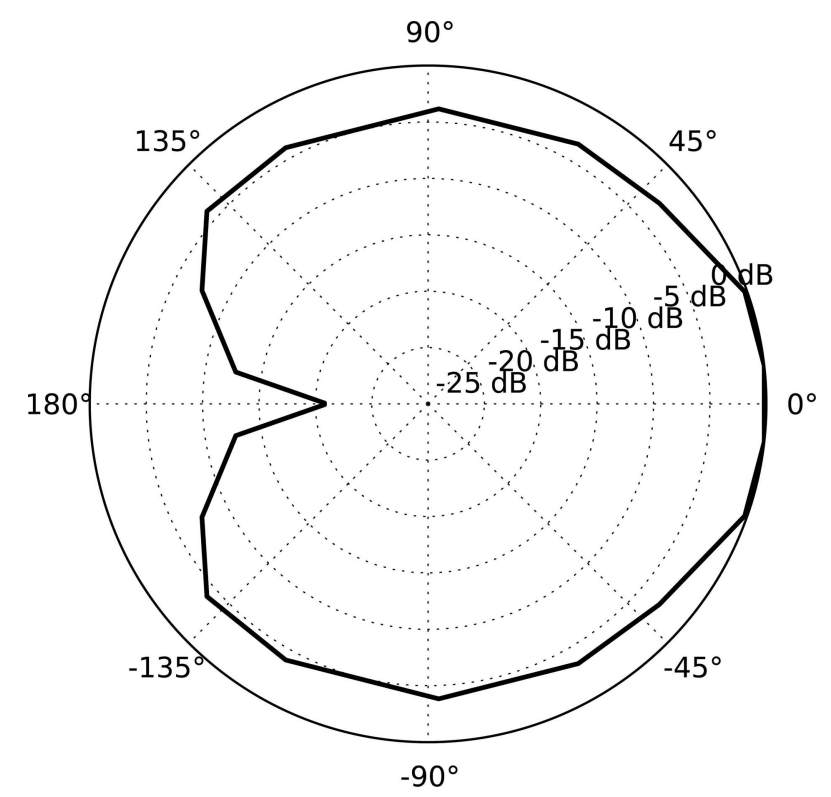

Fig. 7. Angular sensitivity pattern of the IceMole measured during a full-system test in water. $0^{\circ}$ is in front of the IceMole.

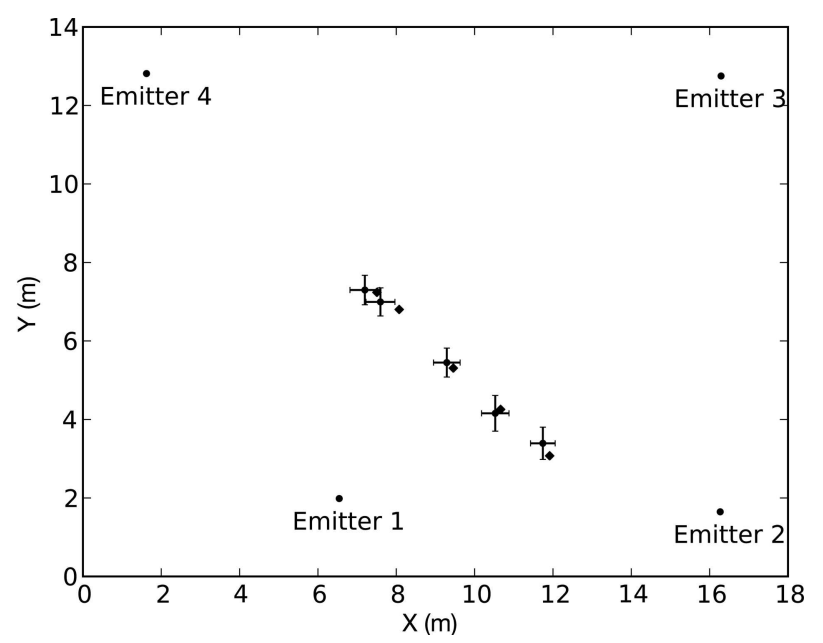

Fig. 8. Reconstructed IceMole positions (circles with errors) in comparison with the position of the raft (diamonds). The errors represent the uncertainties of the trilateration algorithm.

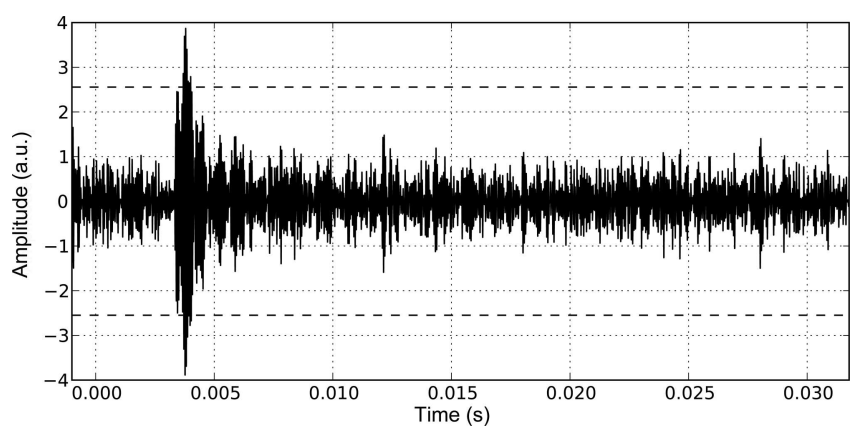

Fig. 9. Signal from one transducer recorded by a receiver within the IceMole head during the field test in summer 2013 on Morteratschgletscher. The horizontal dashed lines mark the signal detection thresholds. The arrival time was determined to $3.7 \mathrm{~ms}$, which corresponds to a distance of $\sim 13 \mathrm{~m}$ using a measured speed of sound of $3600 \mathrm{~m} \mathrm{~s}^{-1}$.

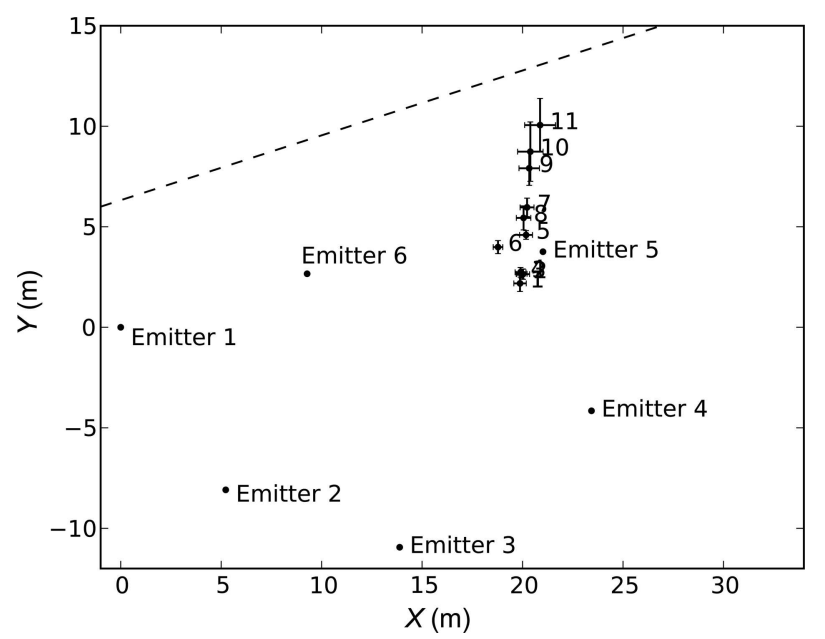

Fig. 10. Reconstructed $20 \mathrm{~m}$ long trajectory recorded during the field test on Morteratschgletscher in summer 2013. The dashed line is a crevasse. 
signal power and by improving the coupling of the receivers and transducers to the ice.

\section{SUMMARY AND OUTLOOK}

The proof of principle of acoustic positioning of a probe in glacier ice was demonstrated. A first APS prototype was developed and integrated into the IceMole. The IceMole, together with the APS, was successfully tested in field tests on glaciers in Switzerland and Antarctica. The system was able to trace trajectories with transducer-receiver distances up to $20 \mathrm{~m}$. The system was then field-tested in summer 2014 (with new sensor electronics and a higher signal power for the transducers, together with new procedures to optimize the transducer coupling and the measurement protocol). Results from the summer 2014 field tests and the autumn 2014 Blood Falls mission will be reported elsewhere.

\section{ACKNOWLEDGEMENTS}

The Enceladus Explorer project is based on an idea and initiative of the DLR Space Administration. It is funded by resolution of the German parliament under project No. 50NA1206. The Enceladus Explorer collaboration comprises the following universities: FH Aachen University of Applied Sciences; RWTH Aachen University; Braunschweig University of Technology; University of Bremen, Bundeswehr University Munich; and University of Wuppertal.

\section{REFERENCES}

Brown RH and 24 others (2006) Composition and physical properties of Enceladus' surface. Science, 311(5766), 1425-1428 (doi: 10.1126/science.1121031)

Dachwald B and 8 others (2014) IceMole: a maneuverable probe for clean in situ analysis and sampling of subsurface ice and subglacial aquatic ecosystems. Ann. Glaciol., 55(65), 14-22 (doi: 10.3189/2014AoG65A004)

IceCube Collaboration (2011) Measurement of acoustic attenuation in South Pole ice. Astropart. Phys., 34(6), 382-393 (doi: 10.1016/ j.astropartphys.2010.10.003)

less $L$ and 10 others (2014) The gravity field and interior structure of Enceladus. Science, 344(6179), 78-80 (doi: 10.1126/ science.1250551)

Meyer M (2011) Signalverarbeitung: analoge und digitale Signale, Systeme und Filter. Vieweg + Teubner Verlag, Wiesbaden, 134-163, 27-286

Mikucki JA and 8 others (2009) A contemporary microbially maintained subglacial ferrous 'ocean'. Science, 324(5925), 397-400 (doi: 10.1126/science.1167350)

Niedermeier $\mathrm{H}$ and 6 others (2014) Navigation system for a research ice probe for Antarctic glaciers. In Proceedings of IEEE Symposium on Position, Location and Navigation (PLANS), 5-8 May 2014, Monterey, CA. Institute of Electrical and Electronics Engineeers, Piscataway, NJ, 959-975

Porco CC and 24 others (2006) Cassini observes the active South Pole of Enceladus. Science, 311(5766), 1393-1401 (doi: 10.1126/science.1123013)

Waite JH Jr and 13 others (2006) Cassini ion and neutral mass spectrometer: Enceladus plume composition and structure. Science, 311(5766), 1419-1422 (doi: 10.1126/science.1121290) 